Retraction

\title{
Retraction: Yu et al. Low Iron Diet Increases Susceptibility to Noise-Induced Hearing Loss in Young Rats. Nutrients 2016, 8, 456
}

\author{
Nutrients Editorial Office \\ MDPI AG, St. Alban-Anlage 66, 4052 Basel, Switzerland; nutrients@mdpi.com \\ Received: 7 April 2017; Accepted: 7 April 2017; Published: 25 April 2017
}

The Nutrients Editorial Office has recently been made aware that the figures in the title paper [1] are taken from the same micrographs as those of other papers by the same authors, but purporting to show different species. In particular, Figure 2D of [1] (rat) is identical to Figure 2D of [2] (mouse), Figure 4B of [1] (rat) is identical to Figure 4B of [3], and Figure 5 of [1] is identical to Figure 3B of [2]. Given this, we do not have confidence in the figures and thus the conclusions of the paper. In order to correct the publication record, the paper [1] will be marked as retracted.

Nutrients is a member of the Committee on Publication Ethics (COPE) and strives to uphold the highest ethical standards; misuse of images is not acceptable and we are committed to taking appropriate action when such cases are reported. We apologize to readers of Nutrients and wish to thank the reader who first reported this case.

\section{References}

1. Yu, F.; Hao, S.; Yang, B.; Zhao, Y.; Yang, J. Low iron diet increases susceptibility to noise-induced hearing loss in young rats. Nutrients 2016, 8, 456. [CrossRef] [PubMed]

2. Yu, F.; Hao, S.; Yang, B.; Zhao, Y.; Zhang, R.; Zhang, W.; Yang, J.; Chen, J. Insulin resistance due to dietary iron overload disrupts inner hair cell ribbon synapse plasticity in male mice. Neurosci. Lett. 2015, 597, 183-188. [CrossRef] [PubMed]

3. Yu, F.; Hao, S.; Yang, B.; Zhao, Y.; Zhang, W.; Yang, J. Mild maternal iron deficiency anemia induces hearing impairment associated with reduction of ribbon synapse density and dysregulation of VGLUT3, myosin VIIa, and prestin expression in young guinea pigs. Neurotox. Res. 2016, 29, 594-604. [CrossRef] [PubMed]

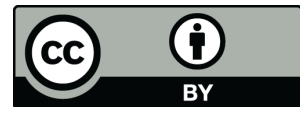

(C) 2017 by the author. Licensee MDPI, Basel, Switzerland. This article is an open access article distributed under the terms and conditions of the Creative Commons Attribution (CC BY) license (http:/ / creativecommons.org/licenses/by/4.0/). 